Vaccine. 2011 August 5; 29(34): 5595-5602. doi:10.1016/j.vaccine.2011.06.020.

\title{
HPV Vaccine and Adolescent Males
}

\author{
Paul L. Reiter, PhD ${ }^{a, b}$, Annie-Laurie McRee, DrPH ${ }^{a}$, Jessica A. Kadis, MPHa , and Noel T. \\ Brewer, PhD ${ }^{a, b}$ \\ a UNC Gillings School of Global Public Health, Chapel Hill, North Carolina \\ ${ }^{b}$ Lineberger Comprehensive Cancer Center, Chapel Hill, North Carolina
}

\begin{abstract}
In 2009, the United States approved quadrivalent HPV vaccine for males 9-26 years old, but data on vaccine uptake are lacking. We determined HPV vaccine uptake among adolescent males, as well as stage of adoption and vaccine acceptability to parents and their sons. A national sample of parents of adolescent males ages $11-17$ years $(n=547)$ and their sons $(n=421)$ completed online surveys during August and September 2010. Analyses used multivariate linear regression. Few sons (2\%) had received any doses of HPV vaccine, and most parents and sons were unaware the vaccine can be given to males. Parents with unvaccinated sons were moderately willing to get their sons free HPV vaccine (mean=3.37, $\mathrm{SD}=1.21$, possible range $1-5$ ). Parents were more willing to get their sons vaccinated if they perceived higher levels of HPV vaccine effectiveness $(\beta=0.20)$ or if they anticipated higher regret about their sons not getting vaccinated and later developing an HPV infection $(\beta=0.32)$. Vaccine acceptability was also modest among unvaccinated sons (mean=2.98, $\mathrm{SD}=1.13$, possible range $1-5$ ). Sons were more willing to get vaccinated if they perceived higher peer acceptance of HPV vaccine $(\beta=0.39)$ or anticipated higher regret about not getting vaccinated and later developing an HPV infection $(\beta=0.22)$. HPV vaccine uptake was nearly nonexistent a year after permissive national recommendations were first issued for males. Vaccine acceptability was moderate among both parents and sons. Efforts to increase vaccine uptake among adolescent males should consider the important role of peer acceptance and anticipated regret.
\end{abstract}

\section{Keywords}

HPV vaccine; Males; Adolescent Health

\footnotetext{
(C) 2011 Elsevier Ltd. All rights reserved.

Correspondence and requests for reprints should be sent to: Paul L. Reiter, PhD, University of North Carolina Gillings School of Global Public Health, Department of Health Behavior and Health Education, 323D Rosenau Hall, CB 7440, Chapel Hill, NC 27599-7440, Tel: 919-966-8650, Fax: 919-966-2921, preiter@email.unc.edu. Second corresponding author: Noel T. Brewer, PhD, University of North Carolina Gillings School of Global Public Health, Department of Health Behavior and Health Education, 325 Rosenau Hall, CB 7440 Chapel Hill, NC 27599-7440, ntb1@unc.edu.

Conflicts of Interest

A research grant to NTB and PLR from Merck Sharp \& Dohme Corp. funded the study. Merck Sharp \& Dohme Corp. played no role in the study design, planning, implementation, analysis, or reporting of the findings. NTB has also received grants and/or honoraria from GlaxoSmithKline and Merck Sharp \& Dohme Corp. PLR has not received honoraria or consulting fees from these companies.

Publisher's Disclaimer: This is a PDF file of an unedited manuscript that has been accepted for publication. As a service to our customers we are providing this early version of the manuscript. The manuscript will undergo copyediting, typesetting, and review of the resulting proof before it is published in its final citable form. Please note that during the production process errors may be discovered which could affect the content, and all legal disclaimers that apply to the journal pertain.
} 


\section{Introduction}

Human papillomavirus (HPV) infection is the most common sexually transmitted infection (STI) in the United States (U.S.) [1]. Prevalence estimates of infection among asymptomatic males are typically over $20 \%$ and range as high as $73 \%$ [2]. Although infection is generally less common among adolescent and young adult males compared to older males [3-5], infection often occurs soon after sexual debut or the introduction of new sexual partners [6]. HPV infections have the potential to cause various adverse health outcomes in males, including genital warts [7,8] and some types of cancer (anal, penile, and oral cancers) [9]. HPV concordance levels are high among sexual partners [10], so infected males also put their female partners at increased risk of cervical disease [11,12].

The U.S. Food and Drug Administration (FDA) approved a quadrivalent HPV vaccine against HPV types 6, 11, 16, and 18 for use in males ages 9-26 in October 2009 [13]. Soon after, the Advisory Committee on Immunization Practices (ACIP) provided a permissive recommendation, allowing for the administration of the 3-dose vaccine series to males ages 9-26 but not making it part of their routine vaccination schedule [13]. The ACIP also recommended HPV vaccine be covered by the Vaccines for Children (VFC) program for eligible males ages 18 or younger [14]. Coverage of the vaccine for males is less clear for private health insurance plans, though not all plans currently provide coverage [15]. The FDA has approved HPV vaccine for genital warts and anal cancer prevention in males $[16,17]$, while the ACIP recommends the vaccine to reduce the likelihood of genital warts in males [13] and is considering its potential to prevent cancer in males. In addition to these individual health benefits, vaccinating males ages 9-26 against HPV also has considerable public health and economic benefits [18].

Studies conducted in the U.S. before HPV vaccine licensure for males found relatively high levels of parental acceptability of the vaccine for their adolescent sons [19]. Our own research conducted soon after vaccine licensure also showed many parents were willing to get their adolescent sons free HPV vaccine [20]. No studies we are aware of, however, have assessed actual HPV vaccine uptake among adolescent males in the U.S. Furthermore, although research has examined vaccine acceptability to male college students and other young adult males [19,21-23], we are not aware of data on acceptability of HPV vaccine to younger adolescent males. Examining vaccine acceptability among this age group is important because HPV vaccine is most effective if given prior to HPV exposure through sexual contact [13], many adolescents are involved in deciding whether they get vaccinated [24], and younger adolescents are the target group for adolescent vaccination platforms [25]. To address these gaps in the existing literature, we collected dyadic data on HPV vaccine uptake and acceptability from parents and their adolescent sons.

\section{Materials and Methods}

\subsection{Study Design}

The HPV Immunization in Sons (HIS) study surveyed parents and their 11-17 year old sons to examine their attitudes and beliefs about HPV vaccination for males. Parents were existing members of a national panel of U.S. households maintained by a survey company [26]. The national panel is a probability-based sample of US households constructed through a dual frame approach (list-assisted, random-digit dialing supplemented by address-based sampling). The survey company provides a laptop and free internet access to non-Internet households so panel members can complete multiple online surveys each month. Panel members in households with existing computer and internet access accumulate points for completing surveys that can later be redeemed for small cash payments. 
We asked participating parents to also allow their sons to participate in our study. For parents with multiple sons ages 11-17, we asked them to answer questions about their son who had the most recent birthday. This same son became eligible for possible participation in the son survey. Parents provided consent for their own participation and their sons' participation prior to the start of the parent surveys. For those parents who provided consent for their sons, we then obtained sons' assent prior to the start of the son surveys.

The survey company invited 1195 parents by email to participate, of whom 752 responded to their invitation. Among those who responded, $73 \%(n=547)$ were eligible and completed the parent survey; 56\% $(n=421)$ had sons who also completed a survey. Sons who did not complete surveys lacked either parents' consent $(n=119)$ or sons' assent $(n=7)$. Participants completed surveys online in August and September 2010. Parents received their standard incentives for participating and sons received 5,000 points ( $\$ 5$ equivalent). The Institutional Review Board at the University of North Carolina approved the study.

\subsection{Measures}

The parent and son surveys are available online at http://www.unc.edu/ ntbrewer/hpv.htm. We developed survey items based on our previous HPV vaccine research among parents, females, and healthcare providers [20,27-29]. We cognitively tested survey items with 6 parent-son dyads, refined the items, and then pretested the survey with 31 parents and 23 adolescent sons. Since our past research indicated that few parents knew HPV vaccine was available for males [20], we provided parents and sons with informative statements about HPV and HPV vaccine throughout the survey. Statements described what HPV is and the diseases it can cause, that HPV vaccine was recently approved for males ages 9-26, the number of doses in the vaccine series, and the potential health benefits the vaccine has for males.

We asked parents and sons if sons had received any doses of HPV vaccine (i.e., vaccine initiation). For parents who indicated vaccine initiation, we asked the main reason why they got their sons the vaccine and how much the first dose of HPV vaccine cost. For parents and sons who did not indicate HPV vaccine initiation, we classified their stage of adoption of HPV vaccination for males [30,31]: (a) unaware: unaware HPV vaccine could given to males; (b) unengaged: aware the vaccine could given to males but had not thought about getting their sons (parent survey) or themselves (son survey) vaccinated; (c): undecided: thought about getting their sons (parent survey) or themselves (son survey) vaccinated but undecided about vaccination in the next year; (d) decided not to act: does not want to vaccinate in the next year; or (e) decided to act: wants to vaccinate in the next year.

The parent survey assessed willingness to get their sons HPV vaccine if it were free using a 5-point scale with responses of "definitely not willing", "probably not willing", "not sure", "probably willing", and "definitely willing" (possible range=1-5). We measured parents' worry about their sons getting HPV-related disease (possible range=1-4), likelihood of their sons getting HPV-related disease (possible range $=1-4$ ), and perceived effectiveness of HPV vaccine against genital warts (possible range $=1-4$ ). Parents indicated how comfortable they were talking with their sons about new vaccines that could prevent cancer or an STI (2 items, $\alpha=0.68$, possible range $=1-5$ ), how much they had talked with their sons about HPV vaccine (possible range $=1-4$ ), whether they thought their sons' insurance covered HPV vaccine, if their sons' doctors ever said their sons should get HPV vaccine, and if they had any daughters ages 9-26 who had received HPV vaccine.

Using items based on the Carolina HPV Immunization Attitudes and Beliefs Scale (CHIAS) [32], the parent survey measured perceived potential harms of HPV vaccine (5 items, $\alpha=0.57$, possible range $=1-5$ ), perceived barriers to getting sons HPV vaccine ( 2 items, 
$\alpha=0.62$, possible range $=1-3$ ), and uncertainty about HPV vaccine ( 3 items, $\alpha=0.55$, possible range $=1-5)$. We assessed parents' anticipated regret if their sons received HPV vaccine and fainted (possible range $=1-4$ ) and if their sons did not get vaccinated and later developed an HPV infection (possible range $=1-4$ ).

The son survey assessed their willingness to get HPV vaccine using a 5-point scale with responses of "definitely not willing", "probably not willing", "not sure", "probably willing", and "definitely willing" (possible range $=1-5$ ). We asked sons 5 HPV knowledge items and classified them as: (a) unaware of HPV (had never heard of HPV before the survey); (b) aware with low HPV knowledge (answered 2 or fewer knowledge items correctly); or (c) aware with high knowledge (answered 3 or more knowledge items correctly). We measured sons' perceived knowledge about HPV vaccine (possible range $=1-4$ ), peer acceptance of HPV vaccine ( 4 items, $\alpha=0.69$, possible range $=1-5$ ), and potential embarrassment if they got vaccinated ( 2 items, $\alpha=0.90$, possible range $=1-5$ ). Using corresponding items and response scales to those on the parent survey, the son survey assessed perceived likelihood of getting HPV-related disease (possible range $=1-4$ ), comfort in talking with their parents about new vaccines ( 2 items, $\alpha=0.71$, possible range $=1-5$ ), how much they had talked with their parents about HPV vaccine (possible range $=1-4$ ), anticipated regret if they got HPV vaccine and fainted (possible range $=1-4$ ), and anticipated regret if they did not get vaccinated and later developed an HPV infection (possible range=1-4).

We collected information on various demographic characteristics (Table 1). We defined "urban" as living in a metropolitan statistical area (MSA) and "rural" as living outside of an MSA [33]. The survey measured parents' political affiliation with responses ranging from "very conservative" to "very liberal" (possible range=1-5) and importance of religion with responses ranging from "not at all important" to "extremely important" (possible range=15). We assessed whether parents were born-again Christians with the item, "Do you consider yourself a born-again or evangelical Christian?" [34].

\subsection{Data Analysis}

We used descriptive statistics to examine HPV vaccine uptake and stage of adoption for parents and sons. We then used linear regression to identify correlates of parents' willingness to get their sons free HPV vaccine and sons' willingness to get vaccinated. Statistically significant bivariate correlates $(p<0.05)$ were entered into a multivariate model for each outcome. We report standardized regression coefficients $(\beta)$ from these linear regressions. We calculated Pearson's correlation coefficient to determine the correlation between parents' and sons' willingness. Analyses of unweighted data used SPSS version 17.0 (SPSS Inc., Chicago IL), and all statistical tests were two-tailed with a critical alpha of 0.05 .

\section{Results}

\subsection{Sample Characteristics}

Most parents were younger than 45 years of age (61\%), non-Hispanic white (67\%), and married or living with a partner (82\%) (Table 1). About half of parents were female (54\%), had at least some college education (56\%), and reported a household income of at least $\$ 60,000$ (49\%). The sample included parents from all four geographic regions of the U.S. and primarily from urban areas $(83 \%)$. Most sons who completed a survey were nonHispanic white $(61 \%)$ and had seen their healthcare provider in the last year (77\%). About $30 \%$ of sons were ages $11-12$, with $38 \%$ ages $13-15$, and $32 \%$ ages $16-17$. Sons who completed surveys had similar characteristics to non-completers, as did their parents (all $p>0.05)$. 


\subsection{Vaccine Uptake and Stage of Adoption}

Only $2 \%(12 / 547)$ of sons had received any doses of HPV vaccine, of which only $2(<1 \%)$ had received all 3 doses. Half of parents with vaccinated sons indicated their main reason for vaccinating was because of a doctor's recommendation $(n=6)$, with fewer reporting genital warts prevention $(n=2)$ or cancer prevention $(n=1)$ as the main reason. All but 1 parent indicated that their sons' health insurance covered all costs for the first dose of HPV vaccine.

Among parents of unvaccinated sons ( $n=535)$, most were in the early stages of adoption, with $80 \%$ unaware that HPV vaccine can be given to males and $13 \%$ unengaged. Few parents were in the later stages of adoption: $2 \%$ were undecided about vaccination in the next year, $1 \%$ did not want to vaccinate their sons in the next year, and $4 \%$ wanted to vaccinate in the next year. Similar to parents, most unvaccinated sons who completed a survey $(n=412)$ were unaware $(90 \%)$ or unengaged $(6 \%)$. Few sons were undecided about vaccination in the next year $(1 \%)$, did not want to get vaccinated in the next year $(1 \%)$, or wanted to get vaccinated in the next year $(2 \%)$.

\subsection{Parents' Willingness to Get Sons HPV Vaccine}

Parents with unvaccinated sons reported fairly low levels of worry and perceived likelihood of their sons getting HPV-related disease (Table 2). Although parents reported high levels of comfort in talking with their sons about new vaccines, they had talked little with their sons about HPV vaccine. Only $21 \%$ of parents thought their sons' health insurance covered HPV vaccine (69\% did not know), and only 3\% reported their sons' doctors said their sons should get HPV vaccine. Parents perceived moderate levels of HPV vaccine effectiveness, potential harms of the vaccine, and barriers to getting their sons vaccinated. Most parents indicated fairly high levels of uncertainty about the vaccine, anticipated regret if their sons got vaccinated and fainted, and anticipated regret if their sons didn't get vaccinated and later got an HPV infection.

Parents with unvaccinated sons reported moderate levels of willingness to get their sons free HPV vaccine (mean $=3.37, \mathrm{SD}=1.21$, possible range $1-5$ ), with $43 \%$ definitely or probably willing to vaccinate. In multivariate analyses, parents were more willing to get their sons free HPV vaccine if they had more liberal political views $(\beta=0.08)$, perceived higher likelihood of their sons getting HPV-related disease $(\beta=0.07)$, had daughters who had received HPV vaccine $(\beta=0.10)$, or were more comfortable talking with their sons about new vaccines $(\beta=0.11)$ (Table 2$)$. Parents were also more willing to vaccinate if they reported higher levels of perceived HPV vaccine effectiveness $(\beta=0.20)$ or anticipated regret if they did not get their sons HPV vaccine and they later became infected $(\beta=0.32)$. Parents were less willing to vaccinate if they perceived more potential harms of HPV vaccine $(\beta=-0.12)$ or reported higher levels of anticipated regret if their sons got vaccinated and fainted $(\beta=$ $-0.14)$.

\subsection{Sons' Willingness to Get HPV Vaccine}

Among unvaccinated sons who completed surveys, most had never heard of HPV before their surveys (75\%), with fewer being aware and having low knowledge (10\%) or high knowledge (16\%) about HPV (Table 3). Similar to parents, sons perceived low likelihood of getting HPV-related disease. Sons were mostly comfortable talking with their parents about new vaccines, but had talked very little with their parents about HPV vaccine and reported low levels of perceived knowledge about the vaccine. Sons indicated moderate levels of peer acceptance of HPV vaccine and potential embarrassment about getting vaccinated. They reported fairly high levels of anticipated regret if they did not get vaccinated and later developed an HPV infection and if they did get vaccinated and fainted. 
Unvaccinated sons were moderately willing to get $\mathrm{HPV}$ vaccine (mean $=2.98, \mathrm{SD}=1.13$, possible range 1-5). Many sons were not sure about vaccination (44\%) and $29 \%$ were definitely or probably willing to get vaccinated. In multivariate analyses, sons were more willing to get HPV vaccine if they reported higher levels of perceived likelihood of getting HPV-related disease $(\beta=0.16)$, peer acceptance of HPV vaccination $(\beta=0.39)$, or anticipated regret if they did not get vaccinated and later developed an HPV infection $(\beta=0.22)$ (Table $3)$. Sons were also more willing to get vaccinated if they had sisters who had received HPV vaccine $(\beta=0.11)$. Sons who indicated higher levels of anticipated regret if they got vaccinated and fainted were less willing to get HPV vaccine $(\beta=-0.26)$.

\subsection{Concordance Between Parents' and Sons' Willingness to Get HPV Vaccine}

Sons' willingness to get vaccinated was positively correlated with their parents' willingness to get them free HPV vaccine $(r=0.52, p<0.001)$. Parents and sons indicated the same level of willingness (e.g., both said "probably willing") in 40\% (166/412) of dyads with unvaccinated sons. In an additional 37\% (152/412) of these dyads, responses provided by parents and sons differed by only one level (e.g., parent said "probably willing" and son said "not sure").

\section{Discussion}

\subsection{Main Findings}

Almost a year after HPV vaccine was licensed and first recommended for males [13], we found that only $2 \%$ of adolescent males had received any doses of HPV vaccine. To our knowledge, this represents the first estimate of HPV vaccine uptake among adolescent males in the U.S. The observed uptake rate is noticeably lower than that among adolescent females about a year after HPV vaccine licensure occurred for them (10\%-30\% in 2007) [35-38]. Vaccination rates among adolescent females have increased in subsequent years, but they remain below 50\% [39] and much lower than other countries [40,41].

HPV vaccination rates may be lower among males within the first year after vaccine licensure compared to females for several reasons. First, the ACIP recommends HPV vaccine be administered routinely to all females aged 11-12 years (with catch-up vaccination for females ages 13-26) [42], which is a stronger recommendation than the current permissive recommendation provided for males [13]. This weaker recommendation could be affecting healthcare providers' and parents' interest in vaccinating adolescent males, as well as coverage of HPV vaccine for males by private health insurance plans [15]. Second, most parents and sons are still in the early stages of adoption of HPV vaccine for males, with over $90 \%$ of parents and sons either unaware or unengaged. In comparison, female college students were in much later stages of adoption (e.g., over 85\% had heard of HPV vaccine) within the first year after vaccine licensure for females [43]. Substantial media coverage about HPV vaccine for females before and soon after vaccine licensure [4446] likely advanced females through the early stages of adoption, whereas media coverage about HPV vaccine for males has been much less. Lastly, HPV vaccine for males was not approved for cancer prevention until recently [17], which is important since framing HPV vaccine as preventing cancer increases men's willingness to receive the vaccine [47]. Education programs for parents and adolescent males are needed to increase their awareness and knowledge about HPV vaccine and allow them to make informed vaccination decisions.

Perceived peer acceptance of HPV vaccine was the strongest correlate of vaccine acceptability among sons. Previous studies among female college students also found peers and social norms were important to HPV vaccine acceptability and uptake [43,48]. Potential embarrassment of getting HPV vaccine was not, however, associated with sons' vaccine 
acceptability in multivariate analyses, suggesting that embarrassment is not a strong potential barrier. Taken together, our results suggest that efforts to normalize HPV vaccination among adolescents, possibly through peer-led programs, may help increase vaccine acceptability among adolescent males.

Additional health beliefs were associated with HPV vaccine acceptability among both parents and sons. Specifically, anticipated regret (of both vaccinating and not vaccinating) and perceived likelihood of sons getting HPV-related disease were important correlates among both groups. Perceived effectiveness and perceived harms of HPV vaccine were additional correlates among parents. Our results are similar to previous HPV vaccine acceptability studies among males (pre-vaccine licensure) [19,21,22] and females [49,50], as well as studies examining HPV vaccine uptake among females [29,51,52]. These modifiable health beliefs, some of which are incorporated in the Health Belief Model (HBM) [53], offer potential targets for future interventions to increase HPV vaccine acceptability and potentially vaccine uptake among males. Educational materials centered around HBM constructs have been well received in promoting influenza vaccination [54]. Given the low awareness and knowledge levels observed in this study, such educational materials may be an important initial strategy for increasing HPV vaccine acceptability and uptake. The use of HBM-based vaccination reminder cards have also been successful in improving vaccination coverage for other vaccines [55] and offer an additional possibility for future HPV vaccine intervention studies.

Doctor's recommendation, an key determinant of HPV vaccine acceptability and uptake among females [29,50], was not associated with parents' acceptability in this study, though this is likely due to so few parents having received a recommendation to get their sons HPV vaccine. Healthcare providers are one of the main sources of HPV vaccine information for parents [56], and they will play an increasingly important role in vaccine acceptability and uptake as time since vaccine licensure for males passes. Future interventions targeting healthcare providers may therefore also help increase HPV vaccine acceptability and uptake among males. For example, physician vaccination reminder systems increase vaccination levels [57] yet are underused by healthcare providers [58].

Parents and sons were more accepting of HPV vaccine if they had daughters (or sisters) who had already received HPV vaccine. These results correspond with those from our past research conducted soon after vaccine licensure [20]. It is likely that these adolescent females getting vaccinated increased parents' and sons' familiarity and general acceptance of HPV vaccine. These findings also suggest that few of the vaccinated females had negative HPV vaccination experiences, which may have lowered parents' and sons' vaccine acceptability. Interestingly, parents' and sons' vaccine acceptability was not correlated with demographic characteristics, including son's age. This differs from studies among females, where HPV vaccine acceptability and uptake have tended to be lower for younger ages $[35,50,59,60]$.

\subsection{Strengths and Limitations}

Our study had many strengths including the use of a national sample, collecting dyadic data on parents and their adolescent sons, refining our surveys extensively through cognitive testing and pretesting, and examining a wide range of potential correlates of vaccine acceptability. Most participants were non-Hispanic white and of fairly high socioeconomic status, though the online panel is very similar to the U.S. population on many demographic features [61]. Panel members also regularly complete surveys, some of which may be health-related, and this could potentially affect their responses. Our estimate of HPV vaccine uptake was based on self-reported data, and willingness levels may overstate future vaccination behavior since intent does not always lead to behavior [51]. We were not able to 
identify correlates of vaccine uptake since so few sons had received any doses of HPV vaccine. Some scales did not have high levels of internal consistency, though this could be partly due to most scales containing only a few items.

\subsection{Conclusions}

In this first examination of HPV vaccine uptake among adolescent males, only $2 \%$ had received any doses of HPV vaccine nearly a year after the vaccine was licensed and first recommended for males. Parents and sons reported moderate levels of vaccine acceptability, and the identified correlates underscore potentially important factors affecting their HPV vaccination decisions. Future interventions are needed to increase HPV vaccine acceptability and uptake among adolescent males.

\section{Acknowledgments}

Supported in part by a research grant from the Investigator-Initiated Studies Program of Merck Sharp \& Dohme Corp. The opinions expressed in this paper are those of the authors and do not necessarily represent those of Merck Sharp \& Dohme Corp. Additional support provided by the American Cancer Society (MSRG-06-259-01-CPPB) and the Cancer Control Education Program at UNC Lineberger Comprehensive Cancer Center (R25 CA57726).

\section{References}

1. Weinstock H, Berman S, Cates W Jr. Sexually transmitted diseases among American youth: incidence and prevalence estimates, 2000. Perspect Sex Reprod Health. 2004; 36(1):6-10. [PubMed: 14982671]

2. Dunne EF, Nielson CM, Stone KM, Markowitz LE, Giuliano AR. Prevalence of HPV infection among men: A systematic review of the literature. J Infect Dis. 2006; 194(8):1044-57. [PubMed: 16991079]

3. Dunne EF, Nielson CM, Hagensee ME, Papenfuss MR, Harris RB, Herrel N, et al. HPV 6/11, 16, 18 seroprevalence in men in two US cities. Sex Transm Dis. 2009; 36(11):671-4. [PubMed: 19809385]

4. Lu B, Hagensee ME, Lee JH, Wu Y, Stockwell HG, Nielson CM, et al. Epidemiologic factors associated with seropositivity to human papillomavirus type 16 and 18 virus-like particles and risk of subsequent infection in men. Cancer Epidemiol Biomarkers Prev. 2010; 19(2):511-6. [PubMed: 20086109]

5. Newall AT, Brotherton JM, Quinn HE, McIntyre PB, Backhouse J, Gilbert L, et al. Population seroprevalence of human papillomavirus types $6,11,16$, and 18 in men, women, and children in Australia. Clin Infect Dis. 2008; 46(11):1647-55. [PubMed: 18444790]

6. Partridge JM, Hughes JP, Feng Q, Winer RL, Weaver BA, Xi LF, et al. Genital human papillomavirus infection in men: incidence and risk factors in a cohort of university students. J Infect Dis. 2007; 196(8):1128-36. [PubMed: 17955430]

7. Brown DR, Schroeder JM, Bryan JT, Stoler MH, Fife KH. Detection of multiple human papillomavirus types in Condylomata acuminata lesions from otherwise healthy and immunosuppressed patients. J Clin Microbiol. 1999; 37(10):3316-22. [PubMed: 10488198]

8. Lacey CJ, Lowndes CM, Shah KV. Chapter 4: Burden and management of non-cancerous HPVrelated conditions: HPV-6/11 disease. Vaccine. 2006; 24(Suppl 3):S3, 35-41. [PubMed: 16950016]

9. Parkin DM, Bray F. Chapter 2: The burden of HPV-related cancers. Vaccine. 2006; 24(Suppl 3):S3, 11-25. [PubMed: 16949997]

10. Reiter PL, Pendergraft WF 3rd, Brewer NT. Meta-analysis of human papillomavirus infection concordance. Cancer Epidemiol Biomarkers Prev. 2010; 19(11):2916-31. [PubMed: 20833971]

11. Bosch FX, Castellsague X, Munoz N, de Sanjose S, Ghaffari AM, Gonzalez LC, et al. Male sexual behavior and human papillomavirus DNA: key risk factors for cervical cancer in Spain. J Natl Cancer Inst. 1996; 88(15):1060-7. [PubMed: 8683637]

12. Habel LA, Van Den Eeden SK, Sherman KJ, McKnight B, Stergachis A, Daling JR. Risk factors for incident and recurrent condylomata acuminata among women. A population-based study. Sex Transm Dis. 1998; 25(6):285-92. [PubMed: 9662761] 
13. Centers for Disease Control and Prevention (CDC). FDA licensure of quadrivalent human papillomavirus vaccine (HPV4, Gardasil) for use in males and guidance from the Advisory Committee on Immunization Practices (ACIP). MMWR Morb Mortal Wkly Rep. 2010; 59(20): 630-2. [PubMed: 20508594]

14. Advisory Committee on Immunization Practices. Vaccines for Children Program - vaccines to prevent human papillomavirus. 2009. Available from: http://www.cdc.gov/vaccines/programs/vfc/downloads/resolutions/1009hpv-508.pdf

15. Haupt, RM.; Sylvester, GC. HPV disease in males and vaccination: Implications and opportunities for pediatricians. Infectious Diseases in Children. 2010. Available from: http://www.pediatricsupersite.com/view.aspx?rid=66396

16. U.S. Food and Drug Administration. Gardasil. 2010. Available from: http://www.fda.gov/BiologicsBloodVaccines/Vaccines/ApprovedProducts/ucm094042.htm

17. U.S. Food and Drug Administration. December 22, 2010 approval letter - Gardasil. 2010. Available from: http://www.fda.gov/BiologicsBloodVaccines/Vaccines/ApprovedProducts/ucm238074.htm

18. Elbasha EH, Dasbach EJ. Impact of vaccinating boys and men against HPV in the United States. Vaccine. 2010; 28(42):6858-67. [PubMed: 20713101]

19. Liddon N, Hood J, Wynn BA, Markowitz LE. Acceptability of human papillomavirus vaccine for males: a review of the literature. J Adolesc Health. 2010; 46(2):113-23. [PubMed: 20113917]

20. Reiter PL, McRee AL, Gottlieb SL, Brewer NT. HPV vaccine for adolescent males: acceptability to parents post-vaccine licensure. Vaccine. 2010; 28(38):6292-7. [PubMed: 20637770]

21. Reiter PL, Brewer NT, McRee AL, Gilbert P, Smith JS. Acceptability of HPV vaccine among a national sample of gay and bisexual men. Sex Transm Dis. 2010; 37(3):197-203. [PubMed: 20118831]

22. Reiter PL, Brewer NT, Smith JS. Human papillomavirus knowledge and vaccine acceptability among a national sample of heterosexual men. Sex Transm Infect. 2010; 86(3):241-6. [PubMed: 19951936]

23. Allen JD, Fantasia HC, Fontenot H, Flaherty S, Santana J. College men's knowledge, attitudes, and beliefs about the human papillomavirus infection and vaccine. J Adolesc Health. 2009; 45(5):5357. [PubMed: 19837363]

24. McRee AL, Reiter PL, Brewer NT. Vaccinating adolescent girls against human papillomavirusWho decides? Prev Med. 2010; 50(4):213-4. [PubMed: 20153358]

25. Middleman AB, Rosenthal SL, Rickert VI, Neinstein L, Fishbein DB, D'Angelo L, et al. Adolescent immunizations: a position paper of the Society for Adolescent Medicine. J Adolesc Health. 2006; 38(3):321-7. [PubMed: 16521332]

26. Dennis, JM. KnowledgePanel Design Summary. 2010. Available from: http://www.knowledgenetworks.com/knpanel/docs/KnowledgePanel(R)-Design-SummaryDescription.pdf

27. Fazekas KI, Brewer NT, Smith JS. HPV vaccine acceptability in a rural Southern area. J Womens Health (Larchmt). 2008; 17(4):539-48. [PubMed: 18370586]

28. Keating KM, Brewer NT, Gottlieb SL, Liddon N, Ludema C, Smith JS. Potential barriers to HPV vaccine provision among medical practices in an area with high rates of cervical cancer. J Adolesc Health. 2008; 43(4 Suppl):S61-7. [PubMed: 18809147]

29. Reiter PL, Brewer NT, Gottlieb SL, McRee AL, Smith JS. Parents' health beliefs and HPV vaccination of their adolescent daughters. Soc Sci Med. 2009; 69(3):475-480. [PubMed: 19540642]

30. Weinstein ND. The precaution adoption process. Health Psychol. 1988; 7(4):355-86. [PubMed: 3049068]

31. Weinstein ND, Sandman PM. A model of the precaution adoption process: evidence from home radon testing. Health Psychol. 1992; 11(3):170-80. [PubMed: 1618171]

32. McRee AL, Brewer NT, Reiter PL, Gottlieb SL, Smith JS. The Carolina HPV Immunization Attitudes and Beliefs Scale (CHIAS): Scale development and associations with intentions to vaccinate. Sex Transm Dis. 2010; 37(4):234-239. 
33. Office of Management and Budget. Standards for defining metropolitan and micropolitan statistical areas; notice. Federal Register. 65(249):82227-82238.

34. Pew Research Center. Question search. Available from: 2010. Available from: http://people-press.org

35. Gottlieb SL, Brewer NT, Sternberg MR, Smith JS, Ziarnowski K, Liddon N, et al. Human papillomavirus vaccine initiation in an area with elevated rates of cervical cancer. J Adolesc Health. 2009; 45(5):430-7. [PubMed: 19837348]

36. Caskey R, Lindau ST, Alexander GC. Knowledge and early adoption of the HPV vaccine among girls and young women: results of a national survey. J Adolesc Health. 2009; 45(5):453-62. [PubMed: 19837351]

37. Centers for Disease Control and Prevention (CDC). Vaccination coverage among adolescents aged 13-17 years - United States, 2007. MMWR Morb Mortal Wkly Rep. 2008; 57(40):1100-3. [PubMed: 18846032]

38. Chao C, Slezak JM, Coleman KJ, Jacobsen SJ. Papanicolaou screening behavior in mothers and human papillomavirus vaccine uptake in adolescent girls. Am J Public Health. 2009; 99(6):113742. [PubMed: 19372507]

39. Centers for Disease Control and Prevention (CDC). National, state, and local area vaccination coverage among adolescents aged 13-17 years --- United States, 2009. MMWR Morb Mortal Wkly Rep. 2010; 59(32):1018-23. [PubMed: 20724968]

40. Brabin L, Roberts SA, Stretch R, Baxter D, Chambers G, Kitchener H, et al. Uptake of first two doses of human papillomavirus vaccine by adolescent schoolgirls in Manchester: prospective cohort study. BMJ. 2008; 336(7652):1056-8. [PubMed: 18436917]

41. Brotherton JM, Deeks SL, Campbell-Lloyd S, Misrachi A, Passaris I, Peterson K, et al. Interim estimates of human papillomavirus vaccination coverage in the school-based program in Australia. Commun Dis Intell. 2008; 32(4):457-61. [PubMed: 19374275]

42. Markowitz LE, Dunne EF, Saraiya M, Lawson HW, Chesson H, Unger ER, et al. Quadrivalent human papillomavirus vaccine: recommendations of the Advisory Committee on Immunization Practices (ACIP). MMWR Recomm Rep. 2007; 56(RR-2):1-24. [PubMed: 17380109]

43. Allen JD, Mohllajee AP, Shelton RC, Othus MK, Fontenot HB, Hanna R. Stage of adoption of the human papillomavirus vaccine among college women. Prev Med. 2009; 48(5):420-5. [PubMed: 19133288]

44. Calloway C, Jorgensen CM, Saraiya M, Tsui J. A content analysis of news coverage of the HPV vaccine by U.S. newspapers, January 2002-June 2005. J Womens Health (Larchmt). 2006; 15(7): 803-9. [PubMed: 16999634]

45. Habel MA, Liddon N, Stryker JE. The HPV vaccine: a content analysis of online news stories. J Womens Health (Larchmt). 2009; 18(3):401-7. [PubMed: 19281323]

46. Kelly BJ, Leader AE, Mittermaier DJ, Hornik RC, Cappella JN. The HPV vaccine and the media: how has the topic been covered and what are the effects on knowledge about the virus and cervical cancer? Patient Educ Couns. 2009; 77(2):308-13. [PubMed: 19395221]

47. McRee AL, Reiter PL, Chantala K, Brewer NT. Does framing human papillomavirus vaccine as preventing cancer in men increase vaccine acceptability? Cancer Epidemiol Biomarkers Prev. 2010; 19(8):1937-44. [PubMed: 20647398]

48. Hopfer S, Clippard JR. College women's HPV vaccine decision narratives. Qual Health Res. 2011; 21(2):262-77. [PubMed: 20841433]

49. Ziarnowski KL, Brewer NT, Weber B. Present choices, future outcomes: anticipated regret and HPV vaccination. Prev Med. 2009; 48(5):411-4. [PubMed: 18996144]

50. Brewer NT, Fazekas KI. Predictors of HPV vaccine acceptability: a theory-informed, systematic review. Prev Med. 2007; 45(2-3):107-14. [PubMed: 17628649]

51. Brewer NT, Gottlieb SL, Reiter PL, McRee AL, Liddon N, Markowitz L, et al. Longitudinal predictors of human papillomavirus vaccine initiation among adolescent girls in a high-risk geographic area. Sex Transm Dis. 2011; 38(3):197-204. [PubMed: 20838362]

52. Daley EM, Vamos CA, Buhi ER, Kolar SK, McDermott RJ, Hernandez N, et al. Influences on human papillomavirus vaccination status among female college students. J Womens Health (Larchmt). 2010; 19(10):1885-91. [PubMed: 20815737] 
53. Becker MH. The Health Belief Model and personal health behavior. Health Educ Monogr. 1974; 2:324-473.

54. Painter JE, Sales JM, Pazol K, Grimes T, Wingood GM, DiClemente RJ. Development, theoretical framework, and lessons learned from implementation of a school-based influenza vaccination intervention. Health Promot Pract. 2010; 11(3 Suppl):42S-52S. [PubMed: 20488968]

55. Hawe P, McKenzie N, Scurry R. Randomised controlled trial of the use of a modified postal reminder card on the uptake of measles vaccination. Arch Dis Child. 1998; 79(2):136-40. [PubMed: 9797594]

56. Hughes J, Cates JR, Liddon N, Smith JS, Gottlieb SL, Brewer NT. Disparities in how parents are learning about the human papillomavirus vaccine. Cancer Epidemiology, Biomarkers \& Prevention. 2009; 18(2):363-372.

57. Briss PA, Rodewald LE, Hinman AR, Shefer AM, Strikas RA, Bernier RR, et al. Reviews of evidence regarding interventions to improve vaccination coverage in children, adolescents, and adults. The Task Force on Community Preventive Services. Am J Prev Med. 2000; 18(1 Suppl): 97-140. [PubMed: 10806982]

58. Tierney CD, Yusuf H, McMahon SR, Rusinak D, O'Brien MA, Massoudi MS, et al. Adoption of reminder and recall messages for immunizations by pediatricians and public health clinics. Pediatrics. 2003; 112(5):1076-82. [PubMed: 14595049]

59. Chao C, Velicer C, Slezak JM, Jacobsen SJ. Correlates for human papillomavirus vaccination of adolescent girls and young women in a managed care organization. Am J Epidemiol. 2010; 171(3): 357-67. [PubMed: 20047978]

60. Reiter PL, Cates JR, McRee AL, Gottlieb SL, Shafer A, Smith JS, et al. Statewide HPV vaccine initiation among adolescent females in North Carolina. Sex Transm Dis. 2010; 37(9):549-56. [PubMed: 20414146]

61. Baker, LC. Validity of the survey of health and internet and Knowledge Network's panel and sampling. 2003. Available from:

http://www.knowledgenetworks.com/ganp/docs/Appendix\%20Survey\%20of\%20Health\%20and $\% 20$ the\%20Internet.pdf 
Table 1

Characteristics of parents $(n=547)$ and their adolescent sons $(n=421)$.

\begin{tabular}{|c|c|}
\hline & $n(\%)$ \\
\hline \multicolumn{2}{|l|}{ Parent Characteristics } \\
\hline \multicolumn{2}{|l|}{ Gender } \\
\hline Female & $294(54)$ \\
\hline Male & $253(46)$ \\
\hline \multicolumn{2}{|l|}{ Age (Years) } \\
\hline$<45$ & $332(61)$ \\
\hline$\geq 45$ & $215(39)$ \\
\hline \multicolumn{2}{|l|}{ Race / Ethnicity } \\
\hline White, Non-Hispanic & $366(67)$ \\
\hline African American, Non-Hispanic & $69(13)$ \\
\hline Hispanic & $83(15)$ \\
\hline Other & $29(5)$ \\
\hline \multicolumn{2}{|l|}{ Marital Status } \\
\hline Divorced, Widowed, Separated, Never Married & $101(18)$ \\
\hline Married or Living with Partner & $446(82)$ \\
\hline \multicolumn{2}{|l|}{ Education } \\
\hline High School Degree or Less & $242(44)$ \\
\hline Some College or More & $305(56)$ \\
\hline \multicolumn{2}{|l|}{ Born-Again Christian } \\
\hline No & $363(66)$ \\
\hline Yes & $184(34)$ \\
\hline Importance of Religion, mean (SD) ${ }^{a}$ & $3.60(1.35)$ \\
\hline Political Affiliation, mean (SD) $b$ & $2.62(0.98)$ \\
\hline \multicolumn{2}{|l|}{ Son Characteristics ${ }^{c}$} \\
\hline \multicolumn{2}{|l|}{ Age (Years) } \\
\hline $11-12$ & $128(30)$ \\
\hline $13-15$ & $158(38)$ \\
\hline $16-17$ & $135(32)$ \\
\hline \multicolumn{2}{|l|}{ Race / Ethnicity } \\
\hline White, Non-Hispanic & $257(61)$ \\
\hline African American, Non-Hispanic & $52(12)$ \\
\hline Hispanic & $68(16)$ \\
\hline Other & $44(11)$ \\
\hline
\end{tabular}

Son Has Seen Regular Healthcare Provider in Last Year

No

95 (23)

Yes

$326(77)$

Household Characteristics

Household Income

$<\$ 60,000$

$279(51)$ 


\begin{tabular}{lc}
\hline & $\boldsymbol{n}(\boldsymbol{\%})$ \\
\hline$\geq \$ 60,000$ & $268(49)$ \\
Urbanicity & \\
Rural & $94(17)$ \\
Urban & $453(83)$ \\
Region of Residence & \\
Northeast & $114(21)$ \\
Midwest & $134(24)$ \\
South & $188(34)$ \\
West & $111(20)$ \\
\hline
\end{tabular}

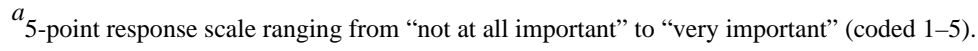

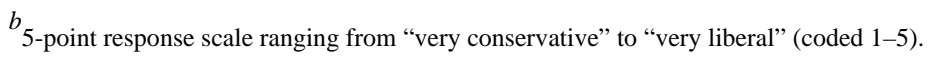

${ }^{c}$ Data collected during parent survey, but we report data only for those sons who completed their own surveys. Sons who completed surveys were similar to non-completers on these characteristics (all $p>0.05$ ). 


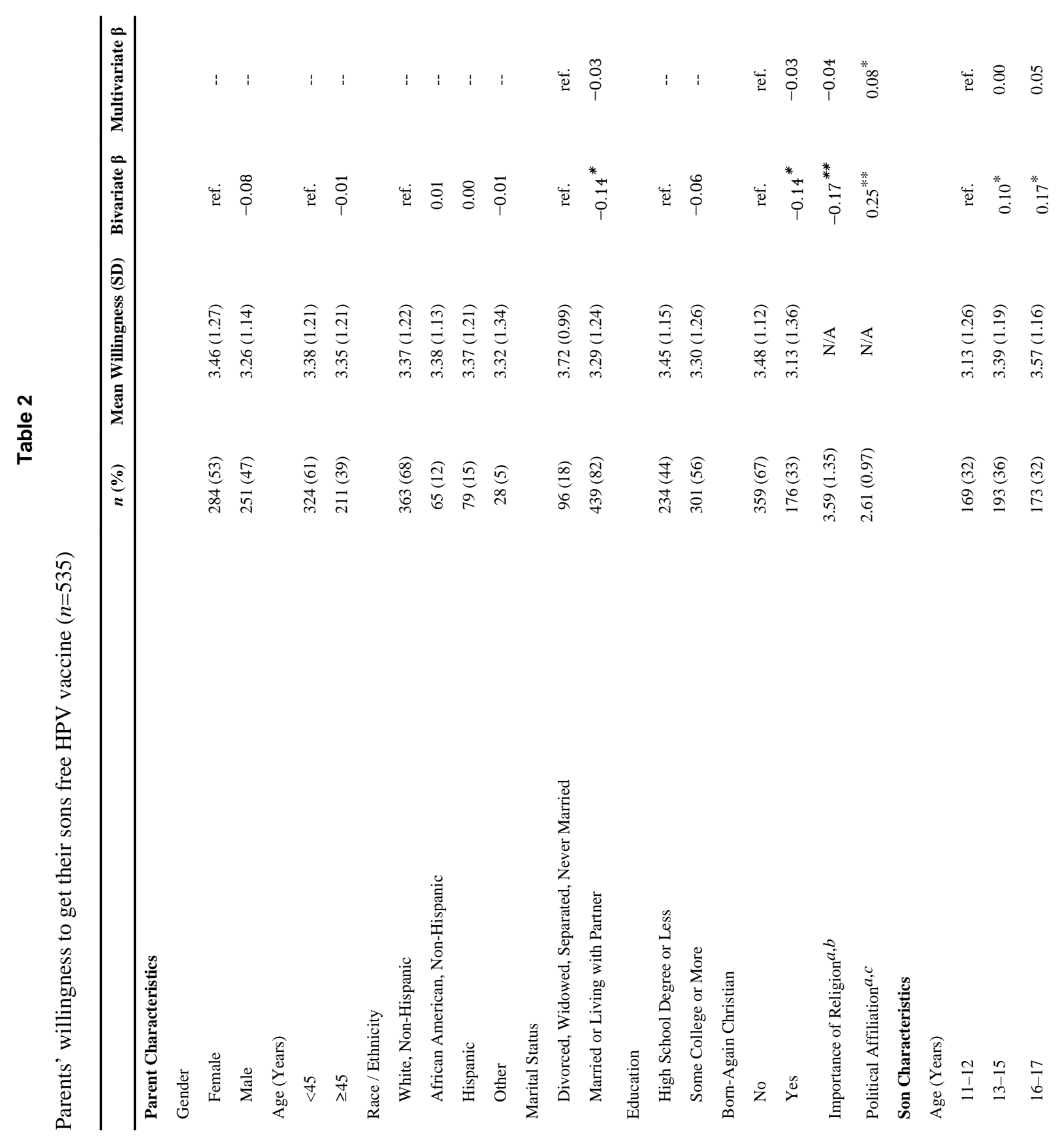


Reiter et al.

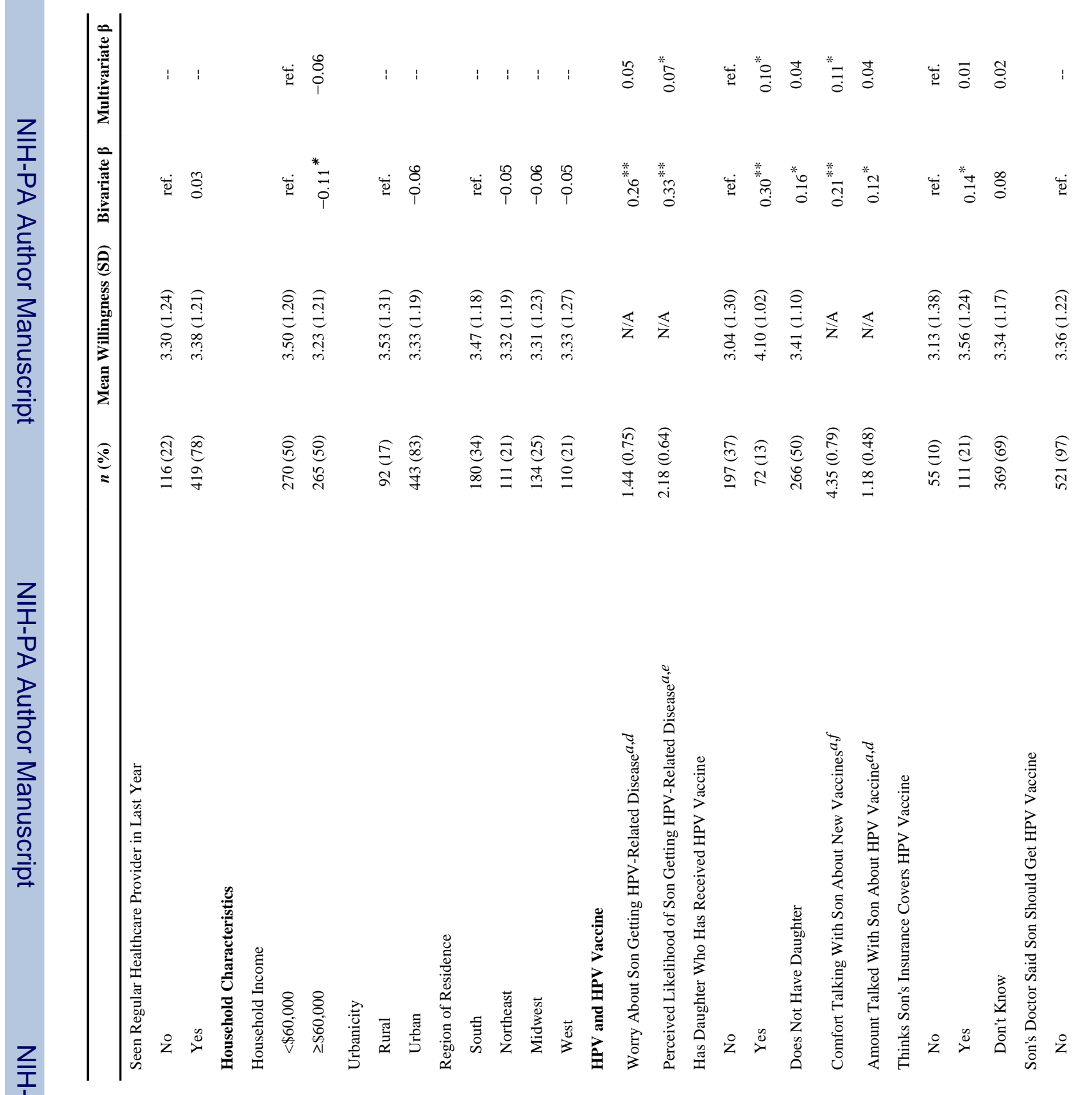




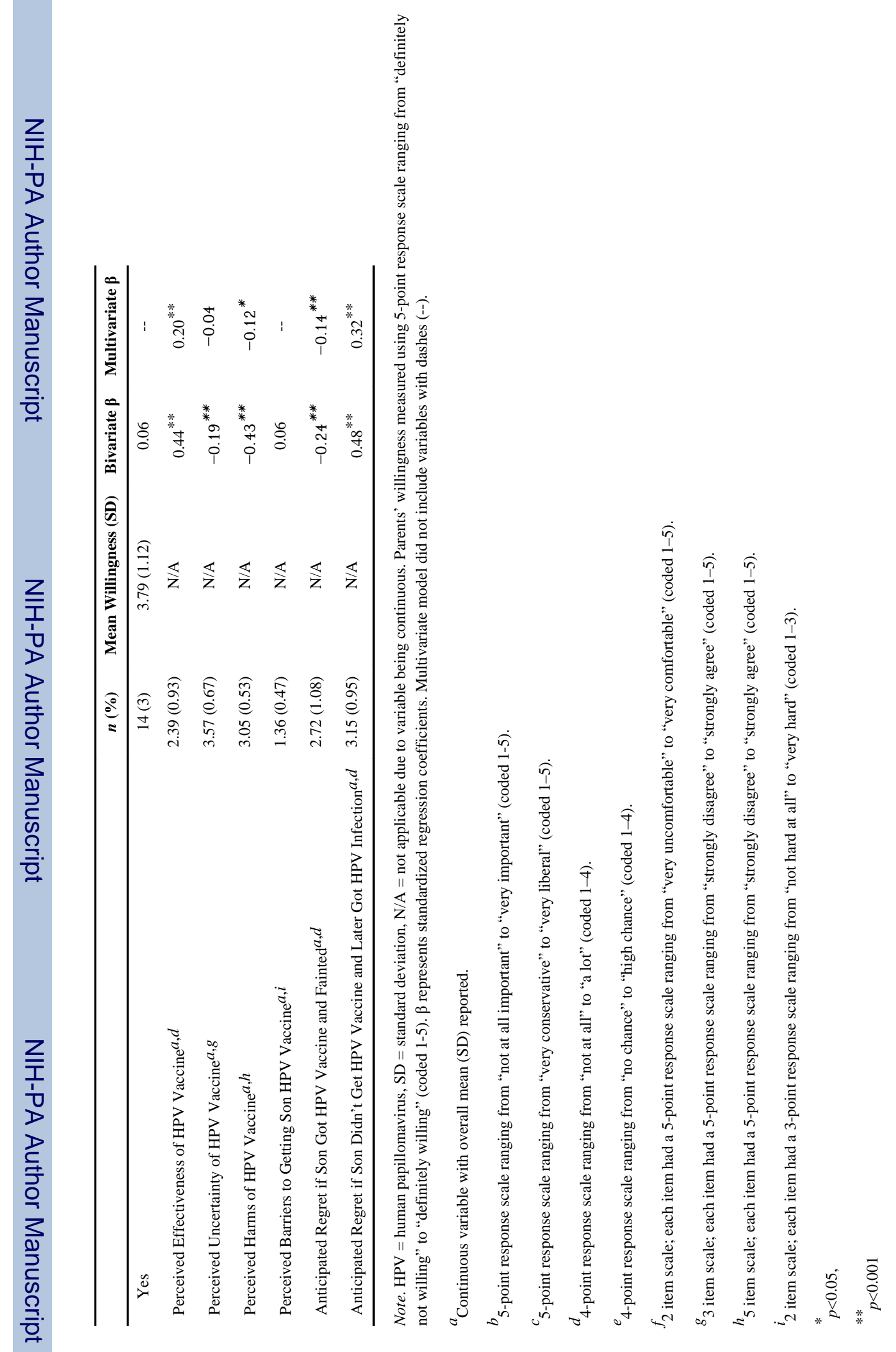




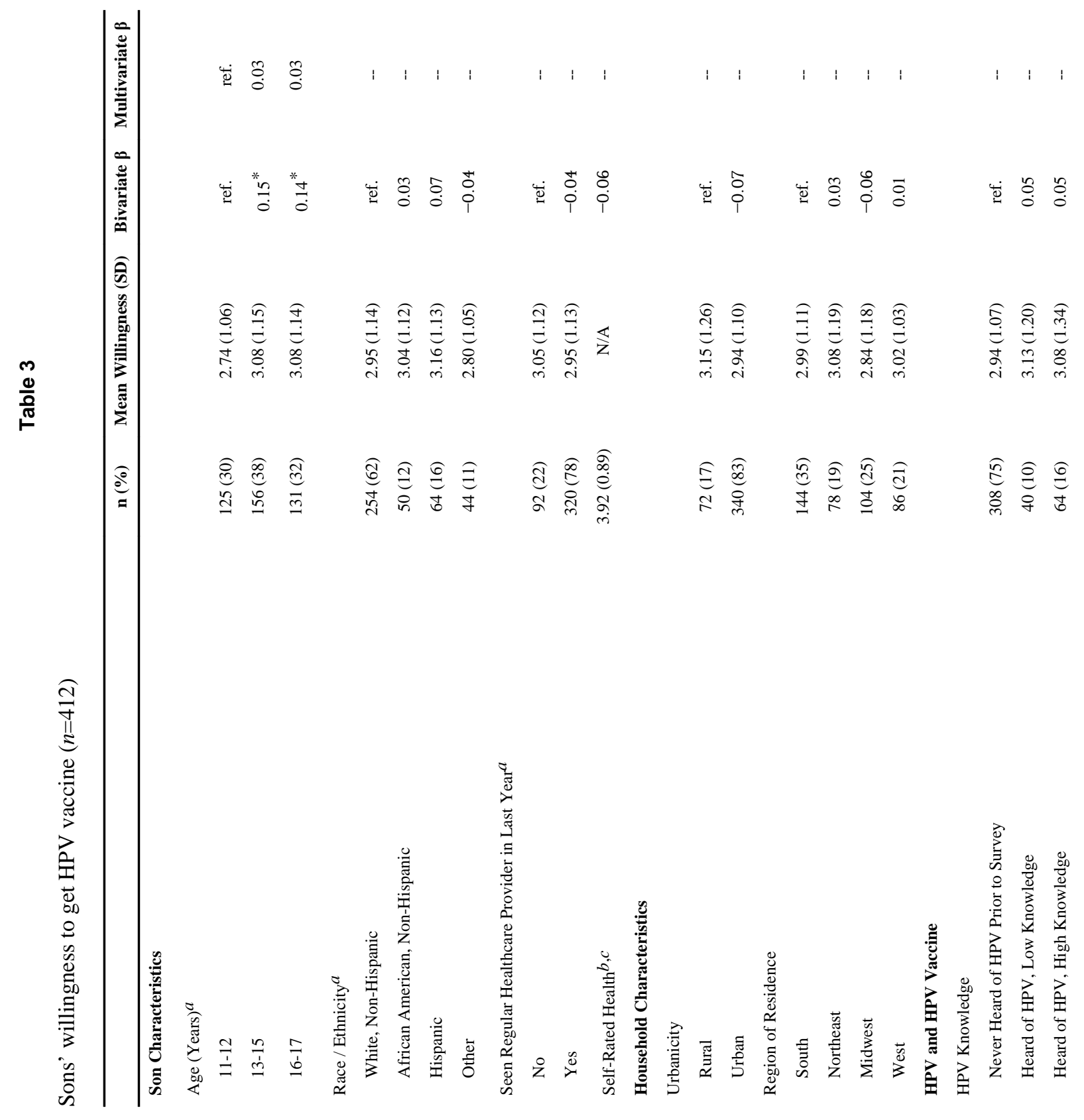




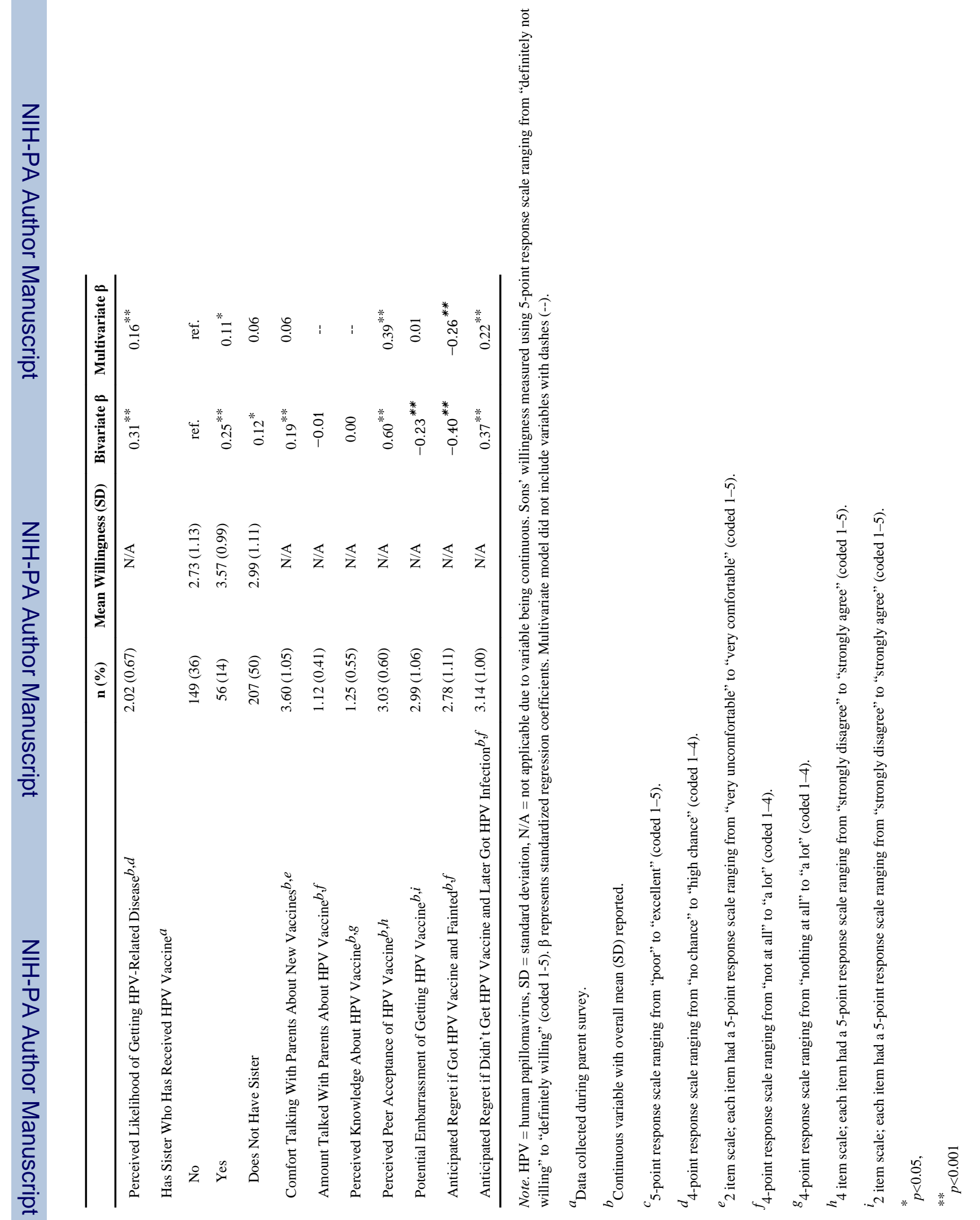

